\title{
Midwives' Views and Perceptions of Patient Dignity in Midwifery Services
}

Tiran Jamil Piro; Department of Midwifery, College of Nursing, Hawler Medical University, Erbil, Iraq.

(Correspondence: tiran.piro@hmu.edu.krd)

\section{ABSTRACT}

Background and objective: Human dignity which is defined as respect to human individuality is a highly recommended necessity to be taken into account in medical settings to deliver high-quality services and raise the patients' satisfaction. Due to a lack of well-defined provisions and instructions in midwifery practice in the Kurdistan region of Iraq, human dignity is threatened in this field. The present study was an attempt to figure out the meaning of patient dignity, what threatens patients' dignity, and how to promote patients dignity in midwifery settings in maternity departments and clinics in Erbil, in the Kurdistan region-Iraq.

Method: The present qualitative study was conducted on 10 Kurdish registered midwives who were working delivery room of Maternity Teaching Hospital and Dyke Private Hospital located in Erbil, Iraqi Kurdistan. In-depth semi-structured interviews were conducted with the midwives to collect required data. The interviews were recorded and then transcribed verbatim and analyzed using the six methodological activities proposed by Van Manen, and the themes and subthemes were extracted.

Results: Analyzing the transcribed interviews resulted in emergence of one main theme, namely "need for holistic support" which had subthemes, namely "need for medical support", "need for mental support", and "need for sympathetic support".

Conclusion: Human dignity of pregnant and childbearing mothers in maternity departments and clinics is relatively low due to lack of sufficient equipment and facilities and insufficient number of midwives and maternity staff. Therefore, appropriate measures need to be taken in these regards.

Keywords: Human dignity, Midwifery, Maternity wards, Pregnancy, Childbearing women

Received: $25 / 08 / 2020$

Accepted: 14/12/2020

Published: 30/05/2021

\section{INTRODUCTION}

Human dignity has been defined as respecting human individuality. In this definition, each individual is regarded to be a unique human being [1]. It is highly recommended that human dignity must be respected in healthcare settings [2]. In the moral codes of midwifery profession, human dignity has been referred to as an obligation and a human right [3]. As a result of human dignity being maintained, a feeling of being valued develops in the individuals, leading to a rise in trust [4]. As defined by the World Health Organization, dignity is the inherent value and worth felt by individuals, and it is strongly linked to freedom of choice, self-worth, recognition, and respect [5].The essence of midwifery is caring which has root in human trait and emotion [6]. The purpose of midwifery caring is to support and help women during childbearing; therefore, the nature of midwifery caring is different from caring in other health professions [7].In midwifery, the quality of caring increases highly once dignity and respect are taken into account [8]. In this regard, it is highly significant for midwifery professionals to create effective interpersonal relationships with their clients [9]. However, it should be noted that there is much 
controversy on the elements of respectful care in midwifery practice [10].Childbirth is a scary and painful experience for most women, which can be relieved by promoting women's emotional wellbeing through provision of quality midwifery care during pregnancy and at birth [11]. Despite the significance of midwifery care, research has indicated that many women have described their encounters with midwives as uncaring [12], and some women have reported that midwives do not usually behave with dignity and respect [13]. There are other reports by pregnant women showing midwifery care lacking emotional support, sympathy, and compassion. In justification of such behavior, some have referred to issues like administrative overload and the organization structure [14].

Patient dignity in midwifery settings has been focused on very few studies. Moreover, the effect of midwives' behavior at workplace on patient dignity has rarely been studied via observation $[15,16]$. According to the results of the studies carried out in the Kurdistan region of Iraq, maternity and midwifery services are negatively affected by professional unaccountability, lack of job description, and limited health resources which in turn have negative impact on the patient's health and dignity [17].Give the significance of human dignity in delivery of quality maternity services and mothers' overall wellbeing, and since human dignity is a complex human phenomenon and can be studied well through individuals' lived experiences, the present study was carried out to investigate the meaning of patient dignity, how patients' dignity is threatened, and how patients' dignity is promoted in midwifery settings.

\section{METHODS}

The present qualitative phenomenological study was carried out by using Van Manen's hermeneutic phenomenological method [18]. from December 2019 to February 2020 to achieve a deep understanding of human dignity of mothers according to midwives working in maternity departments and delivery rooms of Erbil, Iraqi Kurdistan. Phenomenological researchers seek to ask how persons experience their lived world. Max van Manen's Hermeneutic phenomenological approach is especially relevant to nursing research as it provides a way to understand how the persons experience their world. This approach also provides six steps of data analysis which encourages the nursing researchers to craft the texts in order to develop the structure of meaning of the texts or themes. Then, the researchers would be able to understand the meaning of the experience of the participants as they lived in it and the knowledge would provide services or strategies to help them more effectively. The study sample consisted of 10 Kurdish registered midwives who were working delivery room of Maternity Teaching Hospital and Dyke Private Hospital located in Erbil, Iraqi Kurdistan. This number of participants based on data saturation because the goal of qualitative research is achieving data saturation or redundancy. Saturation occurs when adding more participants to the study does not result in obtaining additional perspectives or information. They were selected from among registered midwives by using purposive sampling based on some inclusion criteria: work experience of more than 1 year, speaking and understanding Kurdish, and willingness to participate in the study. Semi-structured in-depth interviews are employed in order to collect required data in phenomenological studies [19]; therefore, the midwives in the present study were interviewed face-to-face. For this purpose and to elicit required information about the interviewees' lived experiences regarding human dignity of mothers, they 
were asked open-ended questions, such as "What do you think about aspects of human dignity according to your experience of working here?" To elicit more detailed information, exploratory questions like how and what questions were used. Kurdish was the language of the interviews

\section{Data analysis}

The transcripts of the interviews were analyzed following the six methodologicalactivities proposed by Van Manen [18] (See Table 1).

Table 1: Van Manen's six methodological activities [18]

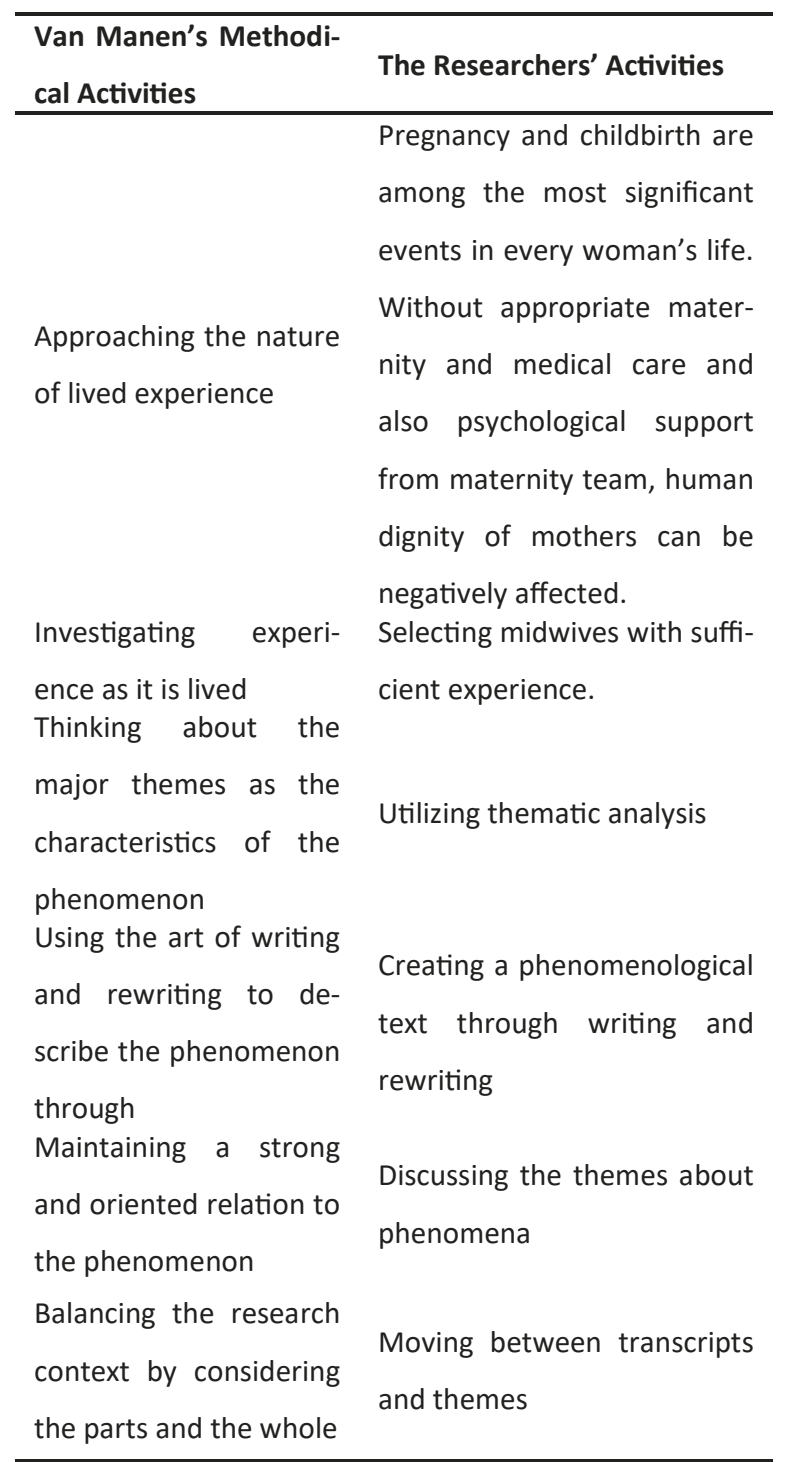

which were recorded at the interviewees' permission and then transcribed verbatim and translated into English for analysis [after obtaining permission from the interviewee]. Each interview lasted between 30 and 60 minutes that was continued until data saturation occurred.

\section{TRUSTWORTHINESS}

Transferability, conformability, dependability, and credibility which are Lincoln and Guba's four-criterion gold standard were used to make sure about the rigor of the study [20]. Also, member- and peerchecking techniques proposed by Devadas (2016) [21] were employed to make sure about the credibility of the findings, which was also ensured through the researcher's prolonged engagement with the data and referral to maternity departments and clinics in Erbil to communicate with the participants effectively and elicit reliable data from them.

\section{ETHICAL CONSIDERATION}

Required approval on the research protocol was obtained from the ethics Committee of Hawler Medical University/ College of Nursing. Moreover, the participants were provided with a thorough explanation about the study's aims, method of data collection, their information confidentiality, and their right to withdraw from the study at any phase. In addition, informed participation consent was obtained from the participants. The midwives also permitted the researcher to record the interviews. Furthermore, each midwife was given a unique code (Midwife 1= M1- Midwife $2,=M 2$, etc.) in order to keep the collected data anonymous. 


\section{RESULTS}

According to study result the selected midwives' age ranged from 25 to 56 years, and their work experience from 1 to 37 years. With regard to their education level, most of them were graduates of midwifery institutes $(n=5)$, some studied midwifery school $(n=4)$, and one of them graduated from university and had bachelor's in midwifery.

Table 2: Below shows the participants' demographic characteristics.

\begin{tabular}{c|c|c}
\hline \multicolumn{1}{c}{ Demographic characteristics } & \multicolumn{1}{c}{$\mathrm{n}(\%)$} \\
\hline \multirow{4}{*}{ Sex } & Female & $10(100.0)$ \\
\cline { 2 - 3 } & Male & $0(0.0)$ \\
\hline \multirow{4}{*}{$\begin{array}{c}\text { Age (years) } \\
\text { dence }\end{array}$} & $25-30$ & $2(20.0)$ \\
\cline { 2 - 3 } & $31-40$ & $3(30.0)$ \\
\cline { 2 - 3 } & $41-50$ & $3(30.0)$ \\
\cline { 2 - 3 } Level of educa- & $51-60$ & $2(20.0)$ \\
\cline { 2 - 3 } tion & Urban & $10(100.0)$ \\
\cline { 2 - 3 } & Rural & $0(0.0)$ \\
\cline { 2 - 3 } & Institute & $5(50.0)$ \\
\cline { 2 - 3 } & Bachelor & $1(10.0)$ \\
\hline \multirow{4}{*}{$\begin{array}{c}\text { Work experi- } \\
\text { ence (years) }\end{array}$} & $1-10$ & $2(20.0)$ \\
\cline { 2 - 3 } & $11-20$ & $3(30.0)$ \\
\cline { 2 - 3 } & $21-30$ & $3(30.0)$ \\
\cline { 2 - 3 } & $31-40$ & $2(20.0)$ \\
\hline
\end{tabular}

\section{Main theme: Need for holistic support}

Analyzing the interview scripts led to the emergence of one main theme which was labeled as "need for holistic support", and it consisted of three subthemes, namely "need for medical support", "need for mental support", and "need for sympathetic support".

The midwives' lived experiences regarding the aspects of human dignity and its status in the studied maternity departments and clinics were interpreted as pregnant women and mothers' need for holistic support. The midwives believed that mothers' human dignity can be raised and maintained if they are provided with comprehensive support which gives them the feeling that they are well-valued. In this regard, Midwife 4 said: "Human dignity can be achieved in many ways. As far as pregnant women are concerned, I guess if they are given sufficient support and help, their human dignity will be ensured. In our maternity department, we pay close attention to mothers' needs and try to meet them. Due to some shortages; however, we may fail to provide full support and meet every single need of the mothers." Comprehensive support was also mentioned by Midwife 7 who stated: "Being pregnant especially for those with their first experience can be quite worrying and apprehensive. However, if comprehensive support is provided, mothers can feel better, which also raises their human dignity by giving them a sense of being valued. Unfortunately, due to various issues, such as huge workload in maternity departments and lack of sufficient maternity staff, comprehensive support and help are sometimes difficult to provide. "First subtheme: Need for medical support One of the most frequent types of support mentioned by almost all of the midwives was medical support. They stated that what mothers expect from them more than anything else is medical help and support. They linked medical support and human dignity by referring to the sense of value that mothers have after receiving a good deal of medical support. In this regard, Midwife 2 said: “I've been working as a midwife for more than 15 years, and I know what makes mothers satisfied. They'd like to be provided with good medical care. I guess provision of good medical care also raises the level of human dignity among mothers." 
Despite the significance of medical care and support, the midwives revealed the fact that their departments were not wellequipped and facilitated, as a result, they sometimes fail to provide sufficient medical care. In this regard, Midwife 5 said: "Our department is undermanned. Also, it is not well-equipped. So, it is quite common that mothers may not receive full medical care, which I'm quite sure has a negative effect on their personality and human dignity." Similarly, Midwife 8 stated: "Maternity wards are usually crowded, and the facilities and equipment are not enough to respond to every single mother's need for medical support fully. In addition to equipment, we need more midwives and maternity staff to provide better maternity services and medical care which will raise our clients' human dignity."

Second subtheme: Need for sympathetic support Another important aspect of support mentioned by most of the midwives was the mothers' need for sympathetic support. They referred to this kind of support as the most important factor in enhancing mothers' human dignity and selfvalue. In this regard, Midwife 1 related: "In addition to maternity care, one thing they need is sympathetic help. This is even more important for those women who are experiencing their first pregnancy. I usually listen to them and try to give them sympathetic support, too. However, given the crowdedness of department and shortage of time, sometimes I'm just able to give them maternity care and advice."

Moreover, Midwife 6 said: "There are just two midwives in our super-crowded delivery room, so we hardly have enough time to spend with the mothers. I know they need something more than maternity and medical care. We need to spend time with them and listen to their concerns and feelings. They sure need our sympathetic support which is helpful for their feeling of human dignity." In addition, Midwife 10 stated: "Respecting mothers along with sympathizing with them can give them the feeling that they are valued. Although I don't have enough time to spend with mothers and sympathize with them, I treat them with full respect and show my sympathy in my behavior. I know it may not be sufficient, but I guess it does the trick and raise the level of their human dignity."

Third subtheme: Need for mental support

Pregnancy can threaten women's mental health if they are not provided with sufficient mental support. This is particularly true about those with their very first experience. Therefore, one of the human responsibilities of maternity team and midwives is to help mothers and pregnant women psychologically. In this regard, Midwife 3 said: "Due to the special cultural structure of Kurdish families, pregnant women in some families do not normally receive appropriate psychological support from their families particularly from their husbands. Therefore, once they refer to us, they are usually in a poor mental state, so in addition to maternity services, we need to prepare them mentally to become a mother. Because in primary health care centers they took just medical support without emotional support or advices. However, again due to the culture in the region, which encourages people to have many children, delivery rooms and maternal wards are always crowded, and midwives do not usually have sufficient time to spend with mothers and provide mental support fully for labor. That is why I suggest hospitals that they employ a psychologist to assist maternity wards and delivery rooms in this regard." In the same regard, Midwife 9 said: "Being pregnant and becoming a mother can be an overwhelming experience. That is why such women need to be supported psychologically. Midwives can provide mental support; however, our 
number one concern is delivering maternity services, so I guess psychological support needs to be provided by someone who specializes in psychology specialty in labor or giving midwives the opportunity to support and advise women before pregnancy until birth not just in labor."

\section{DISCUSSION}

During pregnancy and at birth, mothers need to be treated with dignity and respect. Such dignity should be associated with appropriate maternity care provided by midwives and maternity staff [22]. As a stressful job, midwifery can lead to quick job burnout which in turn can cause low levels of job satisfaction among midwives. Job dissatisfaction can cause midwives to behave in a way that their clients feel they do not receive services and are not valued or respected fully $[23,24]$. As shown by the results of the present study, some issues in maternity wards like high workload and lack of sufficient well-trained maternity staff cause midwives to fail to provide full support to pregnant women and mothers, which can have negative impacts on the level of mothers' human dignity. Research has indicated that promotion of partner involvement, facilitation of new social contacts, pedagogical creativity, emotional confirmation, and a listening and holistic approach by midwives are highly appreciated and welcomed by pregnant women during pregnancy and at childbirth [25]. Moreover, it has been proved that it is highly helpful to provide women with antenatal sessions where they have the chance to have contact and get familiar with the midwives and maternity team. During such sessions, it is also vitally helpful to prepare pregnant women with explanations and feedback on their progress during their pregnancy and labor. The success of such sessions and feedback is highly dependent on the midwives' competence and previous training [26].That is why research has highlighted the need for more competent midwives, pre- and in-service training courses, improvement of working conditions, mental preparation of pregnant women, and appropriate health policies to deliver respectful maternity services and promote human dignity [27]. Since there is not sufficient evidence-based practice in maternity care, a feeling of pressure is experienced by women while trying to receive such care [28].Successful childbirth requires management of the process by a wellexperienced midwife. This process consists of various specialized interventions which should be carried out by enough number of midwives and maternity nurses. In addition to the maternity team, collaboration from the childbearing woman is required, which can be obtained once her human dignity and respect are well attended to in an appropriate environment [29, 30]. In the present study, the midwives referred to issues like overcrowded maternity wards, lack of sufficient equipment and facilities, and lack enough maternity staff. Mentioning these issues, they stated that full medical support and high-quality maternity services cannot be provided, which can have a negative effect on mothers' human dignity and the sense of being valued. In line with this finding, Hall et al. pointed out that the pregnant and childbearing women's independence and dignity can be threatened by the lack of reasonable equipment in midwifery departments and clinics. As a result of such issues in maternity wards, they noticed the explicit statement by women expressing their feeling of being ignored or deprivation from personal choices, and ultimately their human dignity being threatened [31]. Similar issues were referred to by the women in the study carried out by Baranowska et al. who noticed pregnant and childbearing women complaining about maternity care as a result of 
poor communication with and ignorance of their viewpoint by the maternity team [32]. Research has proved the human dignity of mothers rises through constructive communication with the maternity staff. This type of communication is characterized by sympathetic relationships, the staff's willingness and readiness to answer questions posed by mothers, and the allocation of sufficient time to discuss the mothers' concerns [33]. In this regard, caseload care has been proposed to be a successful model in which a single midwife or small group of midwives are assigned to take care of pregnant or childbearing women [34]. In the present study, midwives stated that they do not have enough time to spend with mothers and provide them with sympathetic support because there is a high workload on them; however, some of them try to compensate that gap by respecting mothers and show their sympathy in their behavior. In a similar study carried out by Hall et al., some participants also revealed that the maternity staff did not spend enough time to meet their needs, and no extra support was provided for women with a kind of disability [31]. Similarly, Kozhimannil et al. reported women's complaints about the insufficient time spent by the maternity staff with them which increases their concerns and stress. They also complained about their failure to understand the medical terminology used by the maternity staff [35]. It shows that pregnant and childbearing women need more friendly and passionate relationships and communication within the maternity departments. The psychological stress of pregnant and childbearing women was emphasized by the midwives in the present study, and as they stated, this situation can be relieved by providing mothers with psychological and mental support, which in turn raises their human dignity. However, midwives in this study stated that they did not have enough time to spend with mothers and give them mental help and support, and they suggested that hospitals should employ psychologists for this purpose. Similar to this finding, research has shown that women are highly vulnerable during pregnancy because they usually lose their normal physical abilities and undergo some psychological and social pressures, anxiety, depression, and feeling of uncertainty in life [3638]. The human dignity of this group has not received sufficient attention in the Kurdistan region of Iraq, because very few relevant provisions and instructions are available [39]. Limitation of the present study was just rejection to participate in the study from some midwives because of their individual reasons. It should be stated that some midwives were not willing to take part in the study and discuss their experiences, which could be related to their low trust of the researcher and also their limited time.

\section{CONCLUSION}

The themes that emerged in the present study revealed that the status of human dignity among pregnant and childbearing women in the Kurdistan region of Iraq is not satisfactory due to a lack of sufficient equipment and facilities, barely enough number of well-trained maternity staff and midwives, and crowdedness of the maternity departments.

\section{CONFLICT OF INTEREST}

There is no actual or potential conflict of interest in relation to this study.

\section{REFERENCES}

[1] Ebrahimi H, Torabizadeh C, Mohammadi E, Valizadeh S. Patients' perception of dignity in Iranian healthcare settings: A qualitative content analysis. Journal of Medical Ethics. 2012; 38:723-8. 
[2] Griffin L. An analysis of the concept dignity. Accident and Emergency Nursing. 2005; 13:251-7.

[3] Lam K. Dignity, respect for dignity, and dignity conserving in palliative care. Newsletter - Hong Kong Society of Palliative Medicine. 2007; 3:30-5.

[4] Parandeh A, Khaghanizade M, Mohammadi E, Mokhtari J. Nurses' human dignity in education and practice: An integrated literature review. Iran Journal Nursing Midwifery Research. 2016; 21(1):1-8. doi: 10.4103/1735-9066.174750.

[5] World Health Organization (WHO). World mental health day 2015: Dignity and mental health. Information sheet. Retrieved on August 10, 2020 available at: http:// www.who.int/mental_health/worldmental-health-day/2015_infosheet/en/

[6] Mason E, Mclntosh A, Bryan A, Mason T. Key concepts in nursing. SAGE Publications Inc. 2008, Thousand Oaks, United States.

[7] . Thelin I, Lundgren I, Hermansson E. Midwives' Lived Experience of Caring During Childbirth-A Phenomenological Study. Sexual \& Reproductive Healthcare. 2014; 5: $113-8$

[8] Hall J. Developing a culture of compassionate care-the midwives voice? Midwifery. 2013; 29(4):269-71.

[9] Halldorsdottir S, Karlsdottir I. The primacy of the good midwife in midwifery services: An evolving theory of professionalism in midwifery. Scandinavian Journal Caring Science. 2011; 25: 806-17.

[10] Vogel P, Bohren M. A, Tunçalp O, Oladapo O T, Gülmezoglu A M. Promoting respect and preventing mistreatment during childbirth. International Journal of Obstetrics \& Gynaecology. 2016; 123(5):671-4. doi: 10.1111/1471-0528.13750.

[11] Moberg K U. The Roar Behind the Silence: Why Kindness, Compassion and Respect Matter in Maternity Care 2015; London: Pinter and Martin Ltd.

[12] Bohren M A, Vogel J, Hunter E, Lutsiv O. The mistreatment of women during childbirth in health facilities globally: a mixed methods systematic review. PLOS Medicine. 2015; 12(6): e1001847. doi: 10.1371/ journal.pmed.1001847.

[13] Kana S, Shigeko H, Sebalda L. Yoko S. Midwives' respect and disrespect of women during facility-based childbirth in urban Tanzania: A qualitative study.
Reproductive Health. 2018; 15. 10.1186/ s12978-017-0447-6.

[14] Mathibe JM, Masitenyane SS. Psychosocial Antenatal Care: A Midwifery Context. In: Selected Topics in Midwifery Care. 2018; London, United Kingdom: IntechOpen .

[15] Baillie L. Patient dignity in an acute hospital setting: A case study. International Journal of Nursing Studies. 2008; 46: 23-37. doi: 10.1016/j.ijnurstu.

[16] Hall J, Mitchell M. Dignity and respect in midwifery education in the UK: A survey of Lead Midwives of Education. Nurse Education in Practice. 2016; Volume 21, Pages 915. Available at: https://doi.org/10.1016/ j.nepr.2016.09.003.

[17] Ghiyasvandian S, Piro T. J, Salsali M. Iraqi Nurses' Perspectives on Safety Issues in Maternity Services. Nursing and Midwifery Studies. 2015; 4(3): e29529. doi: 10.17795/ nmsjournal29529.

[18] Zahavi D. The practice of phenomenology: The case of Max van Manen: Journal of Nursing Philosophy. 2019; Volume 21,Issu 2.

[19] Jamshed S. Qualitative research methodinterviewing and observation. Journal of Basic and Clinical Pharmacy. 2014; 5(4):8788.

[20] . Shenton, A. K. Strategies for ensuring trustworthiness in qualitative research projects. Education for Information. 2004; 22: 63-75.

[21] Devadas, B. A Critical Review of Qualitative Research Methods in Evaluating Nursing Curriculum Models: Implication for Nursing Education in the Arab World. Journal of Education and Practice. 2016; 7(7): 2222-88.

[22] Declercq E, Sakala C, Corry M, Applebaum S, Herrlich A. Listening to Mothers III: Pregnancy and Birth. New York: Childbirth Connection; 2013.

[23] . Valizadeh S, Fallahi M, Mohammadi E, Ebrahimi H, Arshadi M. Dignity and respect are the missing link of nurses' empowerment. International Journal of Medical Research \& Health Sciences. 2016; 5, 3:110-15.

[24] Parsa P, Saeedzadeh N, Masoumi S Z, Roshanaei G. The Effectiveness of Counseling in Reducing Anxiety among Nulliparous Pregnant Women. Journal of Family and Reproductive Health. 2016; Vol. 10, No. 4.

[25] Mattern E, Lohmann S, Ayerle G M. Experiences and wishes of women regarding systemic aspects of midwifery care in Germany: a qualitative study with focus groups. BMC Pregnancy Childbirth. 2017; 17: 389. 
doi:10.1186/s12884-017-1552-9.

[26] Hildingsson I, Thomas J E. Women's perspectives on maternity Services in Sweden: processes, problems, and solutions. Journal Midwifery Womens Health. 2007; 52(2):126-33.

[27] Shimoda K, Horiuchi S, Leshabari S, Shimpuku Y. Midwives' respect and disrespect of women during facility-based childbirth in urban Tanzania: a qualitative study. Reproductive Health. 2018; 15, 8. Available at: https://doi.org/10.1186/s12978-0170447-6.

[28] Mattern, E, Lohmann, S, Ayerle, G M. Experiences and wishes of women regarding systemic aspects of midwifery care in Germany: a qualitative study with focus groups. BMC pregnancy and childbirth. 2017; 17(1), 389. https://doi.org/10.1186/ s12884-017-1552-9 .

[29] Bohren M. A, Vogel J P, Hunter E C, Lutsiv O, Makh S K, Souza J P, et al. The mistreatment of women during childbirth in health facilities globally: A mixed? methods systematic review. PLOS Medicine. 2015; 12: e1001847.

[30] Baczek G, Tataj-Puzyna U, Sys D, Baranowska B. Freestanding Midwife? Led Units: A Narrative Review. Iranian Journal of Nursing Midwifery Research. April 2020; 25:181? 8.

[31] Hall J, Hundley V, Collins B, Ireland J. Dignity and respect during pregnancy and childbirth: a survey of the experience of disabled women. Hall. BMC Pregnancy and Childbirth. 2018; 18:328, available at: https://doi.org/10.1186/s12884-018-1950 $-7$.

[32] Baranowska B, Doroszewska A, Kubicka U. Is there respectful maternity care in Poland? Women's views about care during labor and birth. BMC Pregnancy Childbirth. 2019; 19: 520. Available at: https:// doi.org/10.1186/s12884-019-2675-y .

[33] Raine $R$, Cartwright $M$, Richens $Y, M a-$ hamed Z, Smith D. A qualitative study of women's experiences of communication in antenatal care: identifying areas for action. Maternal and Child Health Journal. 2010; 14(4):590-99.

[34] McCourt C. Supporting choice and control? Communication and interaction between midwives and women at the antenatal booking visit. Social Science and Medicine. 2006; 62(6):1307-18.
[35] Kozhimannil K. B, Attanasio L. B., Yang T, Avery $M$, Declercq E. Midwifery care and patient-provider communication in maternity decisions. Maternal\&Child Health. 2015; J. 19(7): 1608-15. doi:10.1007/s10995-0151671-8.

[36] Joolaee S, Nikbakht A, Parsa Z. [Iranian nurses, physicians and patients' lived experiences regarding patient's rights practice (Persian)]. Iran Journal of Nursing. 2009; 22 (60), 28-41.

[37] Toosi M, Akbarzadeh M, Zare N, Sharif N. Effect of attachment training on anxiety and attachment behaviors of first-time mothers. Hayat. 2011; 17:69-79.

[38] Talley L. Stress management in pregnancy. International Journal of Childbirth Education. 2013; 28: 43-5.

[39] Piro T. J. Research Paper: Kurdish Maternity Nurse's Perspectives about Human Dignity. Journal of Client-Centered Nursing Care. 2016; 2(3), 161-168. Available at: https:// doi.org/10.32598/jccnc.2.3.161. 